\title{
Editorial: Seguimos en construcción
}

\author{
Rocío Jiménez-Fontana \\ Editora adjunta. Universidad de Cádiz. \\ rocio.fontana@uca.es \\ ORCID: https://orcid.org/0000-0003-2111-1132 \\ Pilar Azcárate \\ Universidad de Cádiz. Facultad de Ciencias de la Educación. Cádiz España. \\ pilar.azcarate@uca.es \\ ORCID:https://orcid.org/0000-0002-1306-5140
}

\section{We are still under construction}

Para citar este artículo: Jiménez-Fontana, R. y Azcárate, P. (2020) Editorial: Seguimos en construcción. Revista de Educación Ambiental y Sostenibilidad 2(1), $1001 . \quad$ doi: 10.25267/Rev_educ_ambient_sostenibilidad.2020.v2.i1.1001

En la aun corta andadura que lleva nuestra revista, ya hemos detectado la necesidad de nuevas secciones que nos permitan integrar por un lado informaciones y por otro, reflexiones que no han de responder a los formatos habituales de un artículo.

En el primero de los casos abrimos en este número la sección de Reseñas en las que se podrán incluir informaciones sobre diferentes tipos de publicaciones y trabajos de especial relevancia para la Educación Ambiental y de la Sostenibilidad-

Por otro lado, la situación actual ha hecho tambalear más que nunca nuestros cimientos hasta el punto de declarar el estado de alarma en muchos países del mundo. Las consecuencias, catastróficas en muchos aspectos, beneficiosas en algunos otros, son tangibles a diferentes escalas. Sin duda, el 2020 aparecerá en los libros de texto del futuro. Esta tesitura nos ha llevado a considerar la importancia de crear en nuestra revista un altavoz para reflexiones sobre temas trascendentales y de actualidad. Serían escritos que, si bien no responden a los formalismos habituales de investigaciones, estudios o experiencias educativas, sí que son reflejo de reflexiones de actualidad, interesantes y potentes.

Esta nueva sección titulada La Rendija, está dirigida a analizar y reflexionar sobre aspectos educativos de especial actualidad y, en cierta manera, con el foco de atención centrado en las repercusiones en la Educación Ambiental y la Sostenibilidad.

En ambos casos para la presentación de dichos escritos, se debe seguir la plantilla (enlace), y atender a criterios de rigurosidad y fundamentación.

Los presentados para la sección La Rendija, tendrán un máximo de 25.000 caracteres (sin espacios) y serán sometidos a evaluación por pares ciegos.

Esperamos que esta dos nuevas secciones sean de vuestro interés y nos permitan conocer informaciones y reflexiones de interés relevante para los profesionales que nos movemos en este ámbito de la Educación Ambiental y de la Sostenibilidad. 